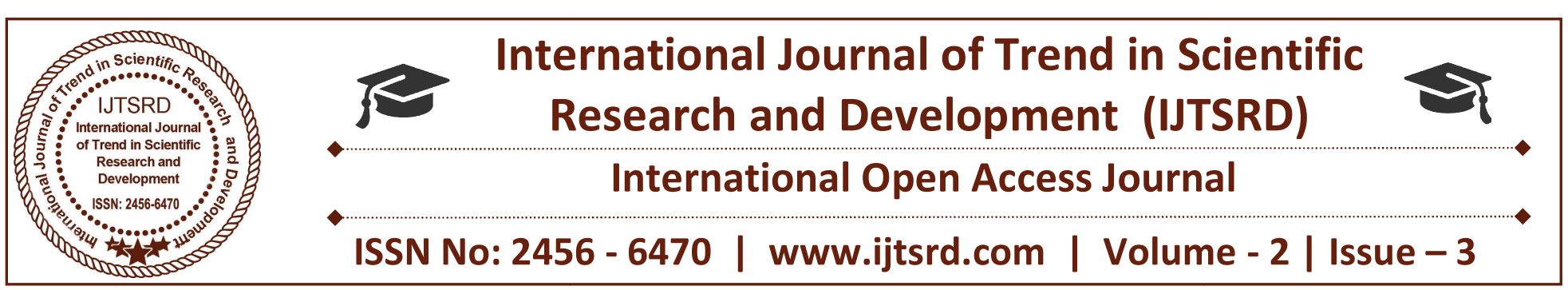

\title{
Optimization of Dry End Milling Process Parameters of Al-6063 Alloy Using Taguchi Method
}

\begin{abstract}
Arun K K
Assistant Professor, Department of Mechanical Engineering, Kumaraguru College of Technology, Coimbatore, Tamil Nadu, India
\end{abstract}

\author{
Ponnuswamy D \\ PG Scholar, Department of Mechanical Engineering, \\ Kumaraguru College of Technology, \\ Coimbatore, Tamil Nadu, India
}

\section{ABSTRACT}

This paper presents on optimizing the end milling process parameters based on the Taguchi method to minimize surface roughness and Tool wear for the work piece of Al-6063 alloy with high speed steel. The input parameters are speed (rpm), feed rate $(\mathrm{mm} / \mathrm{min})$ and depth of cut $(\mathrm{mm})$. $\mathrm{S} / \mathrm{N} /$ ratio is calculated by using Taguchi method under the L9 orthogonal array (OA) with 3 factor and 3 levels. This $\mathrm{S} / \mathrm{N}$ ratio is analysed by analysis of variance (ANOVA), and also find out the effects of control factor with help of analysis of variance. Finally, Results shown that, Taguchi design is the significant method to optimizing the milling process parameters of Speed $1200 \mathrm{rpm}$ with $20 \%$ Significant.

Keyword: ANOVA, End Milling, Surface roughness, Taguchi Method

\section{INTRODUTION}

Milling is one of the basic machining processes which is widely used in the manufacturing industries like Architectural, Window frames, Shop fittings, cycle industries, etc. because it is capable of producing, variety of products with complex geometries. It has generally good mechanical properties and is heat treatable and weld able in al-6063 aluminium alloy. Surface roughness is an important measure of the technological quality of a product and a factor that greatly influences manufacturing cost. [9] To finding out the optimal value of surface roughness and material removal rate by using Taguchi method.[7] used Taguchi and Response Surface Methodologies for minimizing the surface roughness in Turning. Taguchi's parameter design approach has been used to accomplish this objective. Furthermore, a statistical analysis(ANOVA) is performed to see which process parameters are statistically significant.[5] the impact of surface roughness was observed by Feed, Speed and Depth of Cut, there was strong interactions among different end milling parameters.[6] to solve the stated within minimum number of trials as compared with a full factorial design suitable for Taguchi. [4.10]After that find out the Signal to Noise ratios $(\mathrm{S} / \mathrm{N})$ and then analyse the effect of the control parameters in the milling operation. In order to minimize the number of trial experimental, which is used for the Taguchi experimental design approach, a powerful tool for designing high quality system, was developed by Taguchi. The mean response for each run in the inner array, with help of tag chi method. Totally based on statistical design of experiments through the solving and product/process design optimization [1]. It's very easily analysis ANOVA method which is used for Pareto principles. It is a quick and easy method to analyse results of parameter design. [3] It does not require an ANOVA table and therefore does not use $F$-tests. Analysis of variance (ANOVA) is used to identify, which is most significant in this process parameters of end milling machine. 
International Journal of Trend in Scientific Research and Development (IJTSRD) ISSN: 2456-6470

\section{Methodology}

\subsection{Experimental set up}

The experiments were conducted on a HASS CNC vertical Milling machining Centre as shown in Figure 2.1(a). The work piece is placed at the centre of the Machine and held using machine vice.1 GB program memory, 15" colour LCD monitor, USB port, memory lock key switch, rigid tapping and 95 -gallon (360 litter) flood coolant system. The cutting tool high speed steel having four flute $12 \mathrm{~mm}$ diameter $75 \mathrm{~mm}$ shank length of the End mill cutter has been used for experiments. The dimensions of the work piece specimen were taken as $50 \mathrm{~mm} \times 50 \mathrm{~mm}$ and $16 \mathrm{~mm}$. As per experimental design were conducted $\mathrm{L}_{9} \mathrm{OA}$ with help of Three control factor and three levels to assign the experimental date value. Fig 1 Show that Experimental setup for end milling machining process.

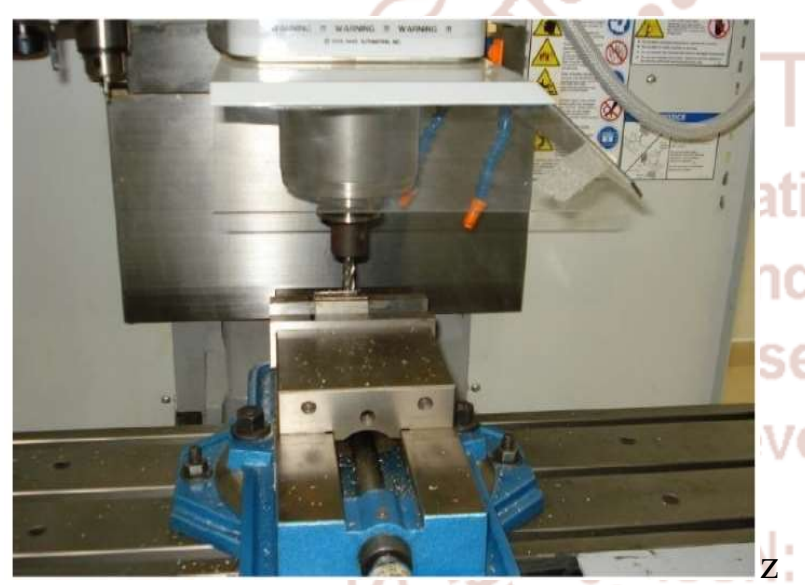

Fig 1 Experimental set up for end milling process
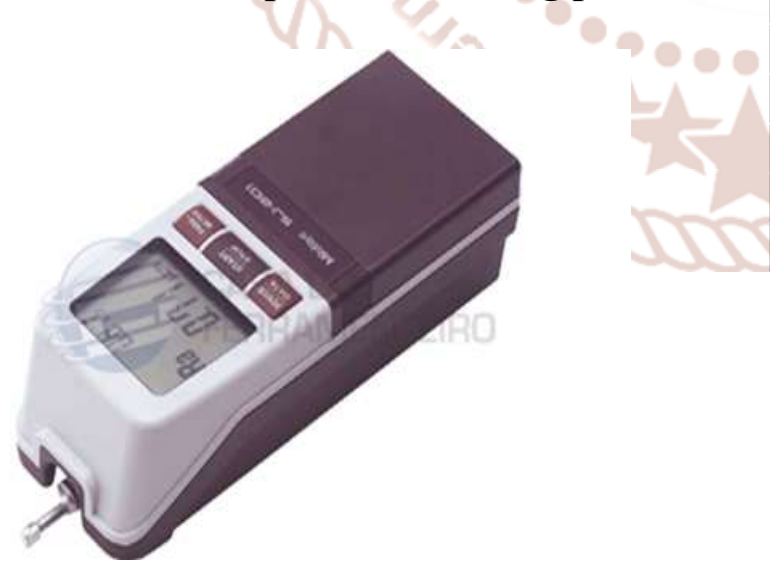

\section{Results and analysis}

\subsection{Taguchi Method}

Fig 2 Surface Roughness Tester mitutoyo (model)
Table 1: End Milling Machining Parameters and levels

\begin{tabular}{|l|l|l|l|l|}
\hline Symbol & Parameters & Level-1 & Level-2 & Level-3 \\
\hline A & $\begin{array}{l}\text { Speed } \\
(\mathrm{rpm})\end{array}$ & 1300 & 1650 & 2000 \\
\hline B & $\begin{array}{l}\text { Feed } \\
(\mathrm{mm} / \mathrm{min})\end{array}$ & 65 & 95 & 125 \\
\hline $\mathbf{C}$ & $\begin{array}{l}\text { Depth of } \\
\text { cut(mm) }\end{array}$ & 0.2 & 0.4 & 0.6 \\
\hline
\end{tabular}

\subsection{Selection of Material}

In recent trend, most of the application using the aluminium 6063 alloy because of less weight ration and also good mechanical properties. This material is heated in Lower temperature it will melted and easily to manufacturing and time consumption is very less obtain. The work piece of Al-6063 alloy dimension is $50 \mathrm{~mm} \times 50 \mathrm{~mm}$ and $16 \mathrm{~mm}$. chemical composition are show in table 2 .

Table 2 chemical composition

\begin{tabular}{|l|l|l|l|l|l|l|l|l|}
\hline $\begin{array}{l}\text { Mn } \\
\%\end{array}$ & $\begin{array}{l}\mathrm{Cu} \\
\%\end{array}$ & $\begin{array}{l}\mathrm{Mg} \\
\%\end{array}$ & $\begin{array}{l}\mathrm{Zi} \\
\%\end{array}$ & $\begin{array}{l}\mathrm{Cr} \\
\%\end{array}$ & $\begin{array}{l}\text { Si } \\
\%\end{array}$ & $\begin{array}{l}\mathrm{Fe} \\
\%\end{array}$ & $\begin{array}{l}\text { Othe } \\
\text { rs }\end{array}$ & Al \% \\
\hline $\begin{array}{l}0.10 \\
\mathrm{~S}\end{array}$ & 0.10 & 0.45 & 0.10 & 0.10 & 0.2 & 0.35 & 0.15 & $\begin{array}{l}\text { Balan } \\
\text { ce }\end{array}$ \\
\hline
\end{tabular}

Table 3 Measured Ra and

\begin{tabular}{|l|l|l|l|l|}
\hline S NO & $\begin{array}{l}\text { Speed } \\
(\mathbf{r p m})\end{array}$ & $\begin{array}{l}\text { Feed } \\
(\mathrm{mm} / \mathrm{min})\end{array}$ & $\begin{array}{l}\text { Depth of } \\
\text { cut }(\mathbf{m m})\end{array}$ & $\begin{array}{l}\text { Ra } \\
(\boldsymbol{\mu m})\end{array}$ \\
\hline 1 & 1300 & 65 & 0.2 & 0.207 \\
\hline 2 & 1300 & 95 & 0.4 & 0.169 \\
\hline 3 & 1300 & 125 & 0.6 & 0.153 \\
\hline 4 & 1650 & 65 & 0.4 & 0.245 \\
\hline 5 & 1650 & 95 & 0.6 & 0.252 \\
\hline 6 & 1650 & 125 & 0.2 & 0.27 \\
\hline 7 & 2000 & 65 & 0.6 & 0.331 \\
\hline 8 & 2000 & 95 & 0.2 & 0.479 \\
\hline 9 & 2000 & 125 & 0.4 & 0.415 \\
\hline
\end{tabular}

This method uses a special design of orthogonal arrays to study the entire parameter space with a minimum number of experiments. Minitab 18 software was used for optimization and graphical analysis of experimental data. In the framework of Taguchi method L18 (OA) has been used in order to explore the process interrelationships within the experimental frame the $\mathrm{OA}$ has 3 columns and 18 
rows. The OA follows a random run order. The run order is a completely random ordering of the experiments which is followed when running the experiments so that experimental error is reduced as far as possible. Taguchi recommends analysing the mean response for each run in the inner array and also suggest to analyse variation using an appropriately selected signal to noise ratio $(\mathrm{S} / \mathrm{N})$. There are three signals to noise ratios

Smaller the better $\left.\mathrm{S} / \mathrm{N}_{\mathrm{SB}}=-10 * \log \left(\Sigma\left(\mathrm{Y}^{2}\right) / \mathrm{n}\right)\right)$

Larger the better 2

Nominal-the-better .............. 3 contrariwise. Taguchi has through empirical observation found that the 2 stage optimisation procedure involving $\mathrm{S} / \mathrm{N}$ ratios so provides the parameter level combination, wherever the quality deviation is minimum whereas keeping the mean not off course.

Table 4 measured $\mathrm{S} / \mathrm{N}$ ratio for $\mathrm{Ra}$

\begin{tabular}{|l|l|l|l|l|}
\hline S No & \multicolumn{1}{|c|}{$\begin{array}{c}\text { Ra } \\
(\boldsymbol{\mu m})\end{array}$} & $\begin{array}{c}\text { TW } \\
(\mathbf{m m})\end{array}$ & SNRA1 & SNRA2 \\
\hline 1 & 0.207 & 0.038 & 13.681 & 28.404 \\
\hline 2 & 0.169 & 0.031 & 15.442 & 30.173 \\
\hline 3 & 0.153 & 0.053 & 16.306 & 25.514 \\
\hline 4 & 0.245 & 0.077 & 12.217 & 22.270 \\
\hline 5 & 0.252 & 0.044 & 11.972 & 27.131 \\
\hline 6 & 0.27 & 0.042 & 11.373 & 27.535 \\
\hline 7 & 0.331 & 0.094 & 9.603 & 20.537 \\
\hline 8 & 0.479 & 0.114 & 6.393 & 18.862 \\
\hline 9 & 0.415 & 0.13 & 7.639 & 17.721 \\
\hline
\end{tabular}

\subsection{Conceptual S/N ratio approach}

$\mathrm{S} / \mathrm{N}=$ signal to noise ratio. $\mathrm{y}_{\mathrm{i}}=$ observed value of the experiment test. $\mathrm{n}=$ number of observation in a trials.

The Taguchi technique is approach a experimental style technique, which is helpful in reducing the quantity of experiments by various victimisation orthogonal arrays and additionally tries to reduce effects of the factors out of management. The basic philosophy of the Taguchi technique is to confirm quality in the style part the best approach of the Taguchi technique area unit to decrease the experimental time, to reduce the price and to search out vital factors in a very shorter period. [12] The most reliable of Taguchi's techniques is that the use of parameter style, that is AN engineering technique for product or method style that focuses on determinative the parameter (factor) settings manufacturing the simplest levels of a high quality characteristic (performance measure) with minimum variation. the general aim of quality engineering is to form periodical set, that relation to all noise factors. the foremost necessary stage within the style of orthogonal array experiment lies within the choice of control factors. As many factors as potential ought to be enclosed so as to that would be potential to spot non-significant variables at the earliest opportunity $[4,8]$. Taguchi creates a typical orthogonal array to accommodate this demand. Taguchi used the quantitative relation $(\mathrm{S} / \mathrm{N})$ ratio because the quality characteristic of choice. $\mathrm{S} / \mathrm{N}$ quantitative relation is employed as a measurable worth instead of standard deviation as a result of because the mean decreases, the standard deviation compared decreases and
Taguchi recommends analysing the effect of the $\mathrm{S} / \mathrm{N}$ ratio magnitude relation using abstract approach that involves graphing the consequences and visually characteristic the factors that seem to be important factor, without victimization ANOVA, therefore creating the analysis simple approach. In this $\mathrm{S} / \mathrm{N}$ ratio, Smaller - the better characterises is used to identify the surface roughness $(\mathrm{Ra})$ at that same Larger-the better is used to identify the material removal rate. In signal to noise ratio is one of the main cretin factor during machining time because of noise will comes from various factors and affect the quality of surface roughness and decrease the material removal rate.

Table 8 Analysis of Variance for $S / N$ ratio of $R a$

\begin{tabular}{|l|l|l|l|l|l|}
\hline Source & DF & Adj SS & $\begin{array}{l}\text { Adj } \\
\text { MS }\end{array}$ & $\begin{array}{l}\text { F- } \\
\text { Value }\end{array}$ & $\begin{array}{l}\text { P- } \\
\text { Value }\end{array}$ \\
\hline $\begin{array}{l}\text { Speed } \\
\text { (rpm) }\end{array}$ & 2 & 79.3930 & 39.696 & 48.70 & 0.020 \\
\hline $\begin{array}{l}\text { Feed } \\
\text { (mm/mi } \\
\text { n) }\end{array}$ & 2 & 0.5757 & 0.2879 & 0.35 & 0.739 \\
\hline $\begin{array}{l}\text { Depth of } \\
\text { cut } \\
\text { (mm) }\end{array}$ & 2 & 6.9908 & 3.4954 & 4.29 & 0.189 \\
\hline Error & 2 & 1.6303 & 0.8152 & & \\
\hline Total & 8 & 88.5899 & & & \\
\hline
\end{tabular}




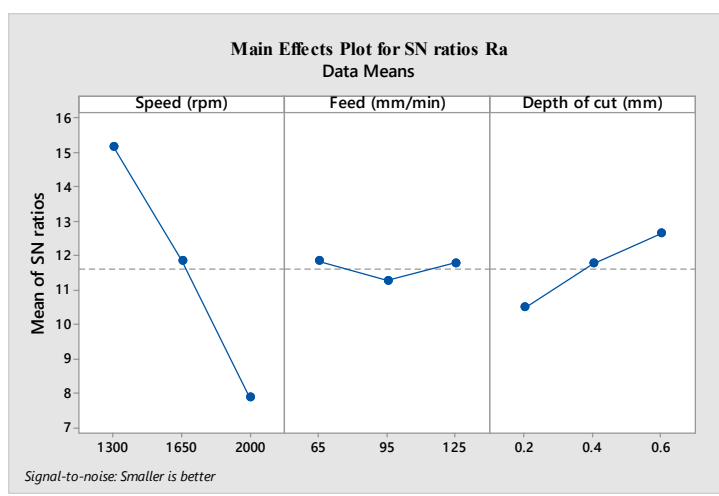

Fig 3 show that $\mathrm{S} / \mathrm{N}$ ratio of $\mathrm{Ra}$ value

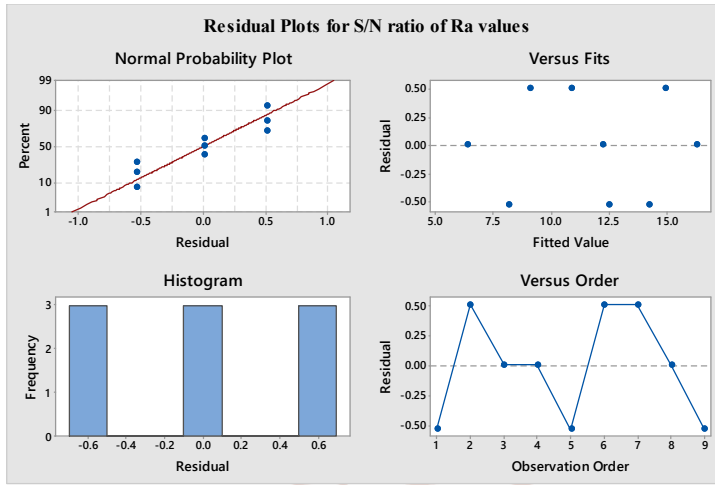

Fig 4 Show that Residual plot for Ra

Fig 4 show that, A residual plot is a graph that is used to examine the goodness-of-fit in ANOVA analysis of variation. This residual plots is to determine whether the ordinary least squares assumptions are being met or not. If these assumptions are satisfied, then ordinary least squares regression will produce unbiased coefficient estimates with the minimum variance.

Histogram to determine whether the data are skewed or whether outliers exist in the data.

Normal probability plot of residuals to verify the assumption that the residuals are normally distributed Residuals versus fits to verify the assumption that the residuals have a constant variance.

Residuals versus order of data to verify the assumption that the residuals are uncorrelated with each other.

\section{Conclusion}

The conclusions derived from optimizing machining parameters and approach in end milling Al-6063 material are as follows. Experiments are performed based on L 9 OA chosen from Taguchi's Method and analysis is done using analysis of variation for optimizing multiple performance characteristics. The optimal level for the control factors was end milling machining of Speed $1200 \mathrm{rpm}$ with feed rate 65 $\mathrm{mm} / \mathrm{min}$ and Depth of cut $0.6 \mathrm{~mm}$. Compared with the experimental values, the optimal Surface roughness of the 9 confirmation sample is $0.150 \mu \mathrm{m}$ which very close to the optimal value of surface roughness 0.157 $\mu \mathrm{m}$.

\section{References}

1) Anyılmaz, M. S. (2006). Design of experiment and an application for Taguchi method in quality improvement activity(Doctoral dissertation, MS Thesis, Dumlupınar University, Turkey).

2) Aslan, Ersan, Necip Camuşcu, and Burak Birgören. "Design optimization of cutting parameters when turning hardened AISI 4140 steel (63 HRC) with A12O3+ TiCN mixed ceramic tool." Materials \& design 28.5 (2007): 1618-1622.

3) Bhattacharya, Anirban, et al. "Estimating the effect of cutting parameters on surface finish and power consumption during high speed machining of AISI 1045 steel using Taguchi design and ANOVA." Production Engineering 3.1 (2009): 31-40.

4) Hassan, Kamal, Anish Kumar, and M. P. Garg. "Experimental investigation of Material removal rate in CNC turning using Taguchi method." International Journal of Engineering Research and Applications 2.2 (2012): 1581-1590.

5) Kaladhar, M., et al. "Application of Taguchi approach and Utility Concept in solving the Multiobjective Problem when turning AISI 202 Austenitic Stainless Steel." Journal of Engineering Science \& Technology Review 4.1 (2011).

6) Kim, Hong Seok. "A combined FEA and design of experiments approach for the design and analysis of warm forming of aluminum sheet alloys." The International Journal of Advanced Manufacturing Technology 51.1-4 (2010): 1-14.

7) Kolahan, Farhad, Mohsen Manoochehri, and Abbas Hosseini. "Simultaneous optimization of machining parameters and tool geometry specifications in turning operation of AISI1045 steel." World academy of science, Engineering and Technology 74 (2011): 786-789.

8) Mariajayaprakash, A., \& Senthilvelan, T. (2012). Process parameter optimization of grate (sugar 
mill boiler) through failure mode and effect analysis and Taguchi method. In Proceedings of International Conference on Advances in Industrial and Production Engineering, AMAE, Bangalore.

9) Nalbant, M., H. Gökkaya, and G. Sur. "Application of Taguchi method in the optimization of cutting parameters for surface roughness in turning." Materials \& design 28.4 (2007): 1379-1385.

10) Thamizhmanii, S., S. Saparudin, and S. Hasan. "Analyses of surface roughness by turning process using Taguchi method." Journal of Achievements in Materials and Manufacturing Engineering 20.1-2 (2007): 503-506.

11) Sankar, R. Siva, et al. "Selection of machining parameters for constrained machining problem using evolutionary computation." The International Journal of Advanced Manufacturing Technology 32.9-10 (2007): 892-901.

12) Shetty, Raviraj, et al. "Study on surface roughness minimization in turning of DRACs using surface roughness methodology and Taguchi under pressured steam jet approach." ARPN Journal of Engineering and Applied Sciences 3.1 (2008): 5967. 